\title{
Response to: DEA in consumer products is safe
}

\author{
Steven H. Zeisel ${ }^{1}$ \\ Department of Nutrition, School of Public Health and Medicine, University of North Carolina, \\ Chapel Hill, North Carolina, USA
}

We thank Dr. Bailey for providing the perspective of the Cosmetic, Toiletry, and Fragrance Association. In our paper we reported that the developing mouse hippocampus was sensitive to dermally administered diethanolamine (DEA) during pregnancy. We used 80 $\mathrm{mg} / \mathrm{kg} / \mathrm{d}$ DEA in these experiments, and we estimated that this exposure was approximately 10-fold higher than likely human exposure. The message of our paper was that, for the first time, DEA was observed to have effects on brain development, and until we know more about this effect it would be prudent for pregnant women to minimize their exposure. Dr. Bailey disputes this, arguing that human skin is less permeable, that the DEA now commonly used in cosmetics is conjugated to a fatty acid, and that humans are not very susceptible to choline deficiency.

Dr. Bailey is mistaken when he states that we reported a no-effect level of $20 \mathrm{mg} / \mathrm{kg} /$ day for the DEA effect on brain development. The only dose we tested was $80 \mathrm{mg} / \mathrm{kg} /$ day and we do not know what the no-effect dose will be; these studies are underway. We agree that estimating the dose exposure to DEA in humans is difficult. We agree with Dr. Bailey that penetration of DEA through human skin is likely to be less than through mouse skin. We administered DEA for only 11 days during pregnancy, many women use DEA-containing products long before they are pregnant and daily throughout pregnancy. The biological half-life of DEA is about 1 week, with steady state for bioaccumulation reached at approximately 4 weeks of dosing (1). Thus, it is likely that our 11 day-dosing procedure underestimated potential exposure. Finally, though shampoos are washed off and do not stay in contact with skin, DEA compounds are also used in sunscreen and skin lotions (2) that are applied to large areas of skin surface and left on the skin. We applied DEA to a small area of skin in our experiments. Note that the lowest dose tested by the National Toxicology Program when they assessed DEA-related carcinogenicity was $10 \mathrm{mg} / \mathrm{kg}$ /day (2). In addition, Dr. Bailey does not address occupational exposure. Occupational exposure to DEA is most likely through the use of lubricating liquids in various processes in machine building; DEA is a component of bulk cutting fluids (3). The National Institute for Occupational Safety and Health estimates that the number of workers potentially exposed to DEA is approximately 800,000 /year (3).

Dr. Bailey points out that many manufacturers have begun using fatty acid conjugates of DEA. We do not know whether such amides have equivalent effects to DEA. The National Toxicology Program has tested DEA-lauryl and reported that it was absorbed across the skin, and that 14 week treatment dermally resulted in modest pathology in the liver of mice (4). The dose with this effect was the molar equivalent of half the dose of DEA we used in our study. Until we know more, we think it is prudent to be cautious.

Finally, Dr. Bailey cites an old reference suggesting that humans are less dependent on choline than are rodents. Recent studies clearly demonstrate that humans are susceptible to choline deficiency (5-12). We estimate that normal choline intake is $750 \mathrm{mg} /$ day in adults. However, Shaw and colleagues, studying pregnant women in California observed intakes that were less than half this amount in $25 \%$ of the women studied (13). Women in this lowest quartile for dietary choline had $4 \times$ the risk of having a baby with a neural tube defect, and $1.6 \times$ the risk of having a baby with a cleft palate $(13,14)$. Thus, there is a real possibility that dietary choline intake during pregnancy is marginal and that exposure to DEA might compromise choline availability further.

\section{REFERENCES}

1. Mathews, J. M., Garner, C. E., Black, S. L., and Matthews, H. B. (1997) Diethanolamine absorption, metabolism and disposition in rat and mouse following oral, intravenous and dermal administration. Xenobiotica 27, 733-746

2. National Toxicology Program. (1999) NTP TR 478: Toxicology and carcinogenesis studies of diethanolamine (CAS No. 11142-2) in F344/N Rats and B6C3F1 mice (dermal studies). Natl. Toxicol. Program Tech. Rep. Ser. 478, 1-212

3. Technology Planning and Management Corporation. (2002) Report on carcinogens background document for diethanolamine. In N01ES85421, p. 229, National Toxicology Program, NIEHS, Durham, NC

4. National Toxicology Program (1999) Toxicology and carcinogenesis studies of lauric acid diethanolamine condensate (CAS NO. 120-40-1) in F344/N rats and B6C3F1 mice (dermal studies). Natl. Toxicol. Program Tech. Rep. Ser. 480, 1-200

5. Da Costa, K. A., Niculescu, M. D., Craciunescu, C. N., Fischer, L. M., and Zeisel, S. H. (2006) Choline deficiency increases

\footnotetext{
${ }^{1}$ Correspondence: CB\#7461, 2115A Michael Hooker Research Center, University of North Carolina at Chapel Hill, Chapel Hill, NC 27599-7461, USA. E-mail: steven_zeisel@unc.edu doi: 10.1096/fj.07-0104ufm
} 
lymphocyte apoptosis and DNA damage in humans. Am. J. Clin. Nutr. 84, 88-94

6. Da Costa, K. A., Kozyreva, O. G., Song, J., Galanko, J. A., Fischer, L. M., and Zeisel, S. H. (2006) Common genetic polymorphisms have major effects on the human requirement for the nutrient choline. Faseb J. 20, 1336-1344

7. Kohlmeier, M., da Costa, K. A., Fischer, L. M., and Zeisel, S. H. (2005) Genetic variation of folate-mediated one-carbon transfer pathway predicts susceptibility to choline deficiency in humans. Proc. Natl. Acad. Sci. USA 102, 16025-16030

8. Da Costa, K. A., Badea, M., Fischer, L. M., and Zeisel, S. H. (2004) Elevated serum creatine phosphokinase in cholinedeficient humans: mechanistic studies in C2C12 mouse myoblasts. Am. J. Clin. Nutr. 80, 163-170

9. Da Costa, K. A., Gaffney, C. E., Fischer, L. M., and Zeisel S. H. (2005) Choline deficiency in mice and humans is associated with increased plasma homocysteine concentration after a methionine load. Am. J. Clin. Nutr. 81, 440-444

10. Buchman, A. L., Ament, M. E., Sohel, M., Dubin, M ., Jenden, D. J.,Roch, M., Pownall, H., Farley, W., Awal, M., and Ahn, C.
(2001) Choline deficiency causes reversible hepatic abnormalities in patients receiving parenteral nutrition: proof of a human choline requirement: a placebo-controlled trial. J. Parenter. Enteral. Nutr. 25, 260-268

11. Buchman, A., Dubin, M., Moukarzel, A., Jenden, D. J., Roch, M., Rice, K. M., Gornbein, J., and Ament, M. E. (1995) Choline deficiency: a cause of hepatic steatosis during parenteral nutrition that can be reversed with intravenous choline supplementation. Hepatology 22, 1399-1403

12. Zeisel, S. H., da Costa, K. A., Franklin, P. D., Alexander, E. A., Lamont, J. T., Sheard N. F., and Beiser, A. (1991) Choline, an essential nutrient for humans. FASEB J. 5, 2093-2098

13. Shaw, G. M., Carmichael, S. L., Yang, W., Selvin, S., and Schaffer, D. M. (2004) Periconceptional dietary intake of choline and betaine and neural tube defects in offspring. Am.J. Epidemiol. 160, 102-109

14. Shaw, G. M., Carmichael, S. L., Laurent, C., and Rasmussen, S. A. (2006) Maternal nutrient intakes and risk of orofacial clefts. Epidemiology 17, 285-291

The opinions expressed in editorials, essays, letters to the editor, and other articles comprising the Up Front section are those of the authors and do not necessarily reflect the opinions of FASEB or its constituent societies. The FASEB Journal welcomes all points of view and many voices. We look forward to hearing these in the form of op-ed pieces and/or letters from its readers addressed to journals@faseb.org. 